\title{
Roger Zuber (16 mai 1931 - 17 juin 2017)
}

\section{Frank Lestringant}

\section{(2) OpenEdition}

\section{Journals}

\section{Édition électronique}

URL : http://journals.openedition.org/studifrancesi/10110

DOI : $10.4000 /$ studifrancesi. 10110

ISSN : 2427-5856

\section{Éditeur}

Rosenberg \& Sellier

\section{Édition imprimée}

Date de publication : 1 décembre 2017

Pagination : 427-428

ISSN : 0039-2944

\section{Référence électronique}

Frank Lestringant, «Roger Zuber (16 mai 1931 - 17 juin 2017) », Studi Francesi [En ligne], 183 (LXI | III) | 2017, mis en ligne le 01 décembre 2018, consulté le 22 janvier 2021. URL : http://

journals.openedition.org/studifrancesi/10110; DOI : https://doi.org/10.4000/studifrancesi.10110

\section{(c) (i) (9)}

Studi Francesi è distribuita con Licenza Creative Commons Attribuzione - Non commerciale - Non opere derivate 4.0 Internazionale. 


\section{Roger Zuber \\ (16 mai 1931 - 17 juin 2017)}

D'une famille originaire de Haute-Alsace, de Mulhouse l'industrieuse plus précisément, le Professeur Roger Zuber parcourut toutes les étapes d'une brillante carrière universitaire. Normalien, il fut d'abord assistant à la faculté des lettres de Strasbourg, assistant puis maître-assistant au collège littéraire universitaire de Reims, Professeur à l'université Mc Gill à Montréal, Professeur de littérature française à l'Université de Paris X-Nanterre, et enfin à Paris IV-Sorbonne, où s'acheva, de 1988 à 1997, sa carrière professionnelle.

Son grand livre, Les Belles infidèles et la formation du goût classique: Perrot d'Ablancourt et Guez de Balzac, essai issu de sa thèse préparée sous la direction de René Pintard, n'est nullement une profession de libertinage, comme le titre pourrait le laisser penser, mais un livre pionnier publié chez Armand Colin en 1968. Centré sur la figure de Nicolas Perrot d'Ablancourt, écrivain protestant au service du roi de France et de Richelieu, qui fut l'un des premiers membres de l'Académie française, à l'époque où tout paraissait pardonné aux réformés rangés protestants rangés sous la monarchie, il inventorie l'œuvre abondante d'un traducteur ou plutôt adaptateur, tour à tour de Tacite, Arrien, Xénophon, César, Lucien et pour finir Thucydide. Sa traduction de Lucien, commente Roger Zuber, n'empêchait pas Perrot d'Ablancourt de s'en prendre aux «lucianistes» sournois, aux défenseurs hypocrites du mauvais maître, ceux-là même qui gravitaient autour de Condé, qui partageaient ses vices et son impiété.

Comment faire passer en français classique une diversité d'auteurs grecs et latins, jugés tantôt trop lourds et redondants, tantôt trop libres et osés, sans les remanier, les travestir et d'une certaine manière les trahir? Paradoxe que ces traductions-trahisons, moins infidèles qu'il n'y parât et moins déplacées qu'il peut sembler aujourd'hui. Contemporain de Jean-Louis Guez de Balzac, Perrot d'Ablancourt dialogue avec le fondateur du classicisme en France, d'accord avec lui sur l'essentiel, le bon goût à instaurer, le tri à opérer chez les maîtres respectés, et l'esprit élégant à établir en toute chose.

Concluant en 1995 la réédition de cet essai magistral, Emmanuel Bury rappelle le rôle déterminant de la traduction dans la naissance du classicisme: «Comme la copie dans les arts plastiques, la traduction est un vecteur essentiel de la diffusion des savoirs et des formes: Roger Zuber prouve que l'étude des "belles infidèles" est une étape indispensable dans toute enquête visant à éclairer une véritable histoire littéraire du classicisme français et, au-delà, à comprendre le sens que prend l'invention d'une nouvelle littérature dans une tradition pluriséculaire» ${ }^{1}$.

Cet ouvrage fut ensuite prolongé dans Les Émerveillements de la raison. Théorie et critique à l'âge classique, recueil d'études savantes publié une trentaine d'années plus tard chez Klincksieck, et qui résume une carrière de chercheur, tout en l'élar- 
gissant vers les littératures minoritaires, en particulier la littérature des prétendus réformés, comme on disait à l'époque ${ }^{2}$. Sous la plume de «Zuber le bref», comme le dit plaisamment le surnom qu'il revendiquait, Lucien toujours revient, mais le cercle littéraire s'élargit désormais à Racine et Boileau, notamment dans l'article «La Tragédie sublime: Boileau adopte Racine».

En quoi le classicisme est-il donc libre? demande Roger Zuber. Libéré des contraintes que l'on a dit, bien à tort, procéder de lui, il ne renonce ni à séduire ni à émerveiller. Cette attitude d'émerveillement, explique-t-il, «était déjà celle de beaucoup de Romains par rapport aux Grecs, de beaucoup de poètes alexandrins par rapport aux poètes archaïques, d'un sophiste comme Lucien par rapport aux tragiques et aux comiques d'Athènes. On peut parodier ses maîtres, on peut les plaisanter, on peut surtout, en les imitant, le faire avec le sourire»".

Roger Zuber me souhaitait à la Sorbonne, dont l'helléniste Jacques Bompaire, un autre protestant, était le Président. Je me souviens du jour où il voulut m'entretenir dans son bureau, ou plutôt dans l'étroit bureau qu'il partageait avec d'autres collègues. Nous montâmes deux étages, puis encore un. Il poussa la porte, et aussitôt nous fûmes en présence d'un groupe nombreux, serré, travaillant, rangé autour du Professeur Robert Garapon qui présidait. Il s'agissait sans doute d'une séance de délibération à la suite des examens de juin. La porte fut promptement et doucement refermée. Notre rendez-vous prit fin de ce fait même. Nous redescendîmes en silence les escaliers, et dans la rue prîmes congé l'un de l'autre. Peu de temps après, Roger Zuber prit sa retraite, et j'entrai à mon tour à la Sorbonne.

La retraite de Roger Zuber fut tout autre chose qu'une sinécure. C'est à cette occasion qu'il présida de 1990 à 1996 la Société d'histoire du protestantisme français, d'une main ferme mais toujours bienveillante. Dans ce cadre, il avait organisé avec d'autres le grand colloque de 1985 qui commémorait la Révocation de l'édit de Nantes, colloque qui fit date dans les études sur le protestantisme en France sous le Roi-Soleil.

Roger Zuber s'est à présent retiré. Laissons-le conclure à propos de Pierre Bayle, l'encyclopédiste protestant: "La profession du protestantisme, dit le Dictionnaire de Bayle à propos de l'hébraïsant Drusius, est ruineuse selon le monde. Elle ne [...] donne rien, et $[\ldots]$ prive de cent avantages qu'on se procurerait en la quittant". Constat banal, et pour l'époque, et quant à la condition d'un lettré sans emploi. Pierre Bayle, qui était chatouilleux sur les questions d'honneur, ne pouvait pas trahir. À la fierté du minoritaire s'adjoint l'orgueil de l'élection. Nous dirions finalement que Bayle protestant est un homme fidèle à lui-même. La sensibilité d'un réformé français lui est restée consubstantielle, à travers les aventures de sa pensée. Il y a quelque chose de presque ethnique dans cette identité. Et le fait qu'elle se soit maintenue au Refuge et hors de France, chez un prince de l'esprit, montre bien la solidité de ce qui la fondait, dans les générations antérieures alors fixées en France» .

Le protestantisme de Roger Zuber ne saurait faire oublier son amour serein de la littérature. Son extrême politesse n'était que l'expression d'une extrême pudeur. Sa sollicitude attentive était tempérée par la retenue. Sa réserve recelait une sympathie véritable, combattue par le sens des formes et le respect d'autrui, mais se révélant soudain dans un rire éclatant et clair.

FRANK LESTRINGANT

(2) R. Zuber, Les Émerveillements de la raison, Paris, Klincksieck, 1997.

(3) Ibid., p. 303.

(4) R. ZUBER, «Bayle protestant», in Les Éclaircissements de Pierre Bayle. Édition des Éclaircissements du Dictionnaire historique et critique et études critiques recueillies par Hubert Bost et Anthony Mc Kenna, Paris, Honoré Champion, 2010, pp. 235-240; cité p. 240. 